\title{
Levantamento do Banco de Sementes em Dois Sistemas de MANeJo de Solo IRRIgados POR Pivô Central ${ }^{1}$
}

\author{
Seeds Bank Assessment under Two Systems of Management of Soil Irrigated by Central Pivot
}

\author{
LACERDA, A.L.S. ${ }^{2}$, VICTORIA FILHO, R. ${ }^{3}$ e MENDONÇA, C.G. ${ }^{4}$
}

\begin{abstract}
RESUMO - Os objetivos desta pesquisa foram fazer o levantamento da população vegetativa e determinar o número de sementes viáveis e sua distribuição no perfil do solo em área sob dois sistemas de manejo de solo. Para isso, foram realizados no Departamento de Produção Vegetal da ESALQ/USP dois ensaios condicionados a dois tipos de preparo de solo: convencional e pousio. Para análise estatística foram retiradas 28 amostras de cada tipo de solo (convencional e pousio), sendo as médias comparadas pelo teste $\mathrm{t}$ a $5 \%$ de probabilidade. A identificação da população vegetativa e a quantidade de sementes viáveis e sua distribuição no perfil do solo foram determinadas pela retirada de 20 amostras simples de solo nas profundidades de $0,0-2,5 ; 2,5-5,0 ; 5,0-10,0 ; 10,0-15,0 ;$ e $15,0-20,0 \mathrm{~cm}$, sendo acondicionadas em bandejas de alumínio e avaliadas em quatro épocas: aos 15, 30, 60 e 90 dias em casa de vegetação. Na área de pousio ocorreu menor número de espécies e sementes viáveis no solo. As famílias dominantes foram Compositae e Amaranthacea e as sementes concentraram-se nas camadas superficiais do solo $(0-2,5 \mathrm{~cm})$. $\mathrm{Na}$ área convencional, as famílias dominantes foram Compositae e Cruciferaceae e as sementes viáveis encontraram-se dispersas no perfil do solo.
\end{abstract}

Palavras-chave: banco de sementes, perfil de solo, plantas daninhas.

\begin{abstract}
The objective of this work was to assess the vegetative population and to determine the number of viable seeds and their distribution in the soil profile under two soil management systems. Thus, two assays were conducted at the Department of Vegetable Production of ESALQ/ USP using two types of soil preparation systems: tillage and no-tillage. For statistical analysis 28 samples of each type of soil handling were removed (tillage and pousio), being the averages compared by the test $t$ to $5 \%$ of probability. The identification of the vegetative population and the amount of viable seeds and their distribution in the soil profile was determined by collecting the soil samples at depths of 0.0-2.5, 2.5-5.0, 5.0-10.0, 10.0-15.0 and 15.0-20.0 cm, placing them in aluminum trays and evaluating them in 15, 30, 60 and 90 days under greenhouse conditions. In the no-tillage system area, a smaller number of weed species and viable seeds occurred in the soil. The dominant families were Compositae and Amaranthacea and the seeds concentrated on the superficial layers of the soil $(0-2.5 \mathrm{~cm})$. In the tillage system area the dominant families were Compositae and Cruciferaceae and the viable seeds were dispersed in the soil profile.
\end{abstract}

Key words: seed bank, soil profile, weeds.

1 Recebido para publicação em 21.102004 e na forma revisada em 21.04.2005.

2 Eng.-Agrônomo, D.S. em Fitotecnia, Rua Padre Francisco de Abreu Sampaio, 269, 13030-350 Campinas-SP, <alslacer@esalq.usp.br>. ${ }^{3}$ Prof., D.S., Titular do Dep. de Produção Vegetal, ESALQ/USP, Av. Pádua Dias 11, Caixa Postal 9, 13417-950 Piracicaba-SP, <rvictori@esalq.usp.br>. ${ }^{4}$ Prof ${ }^{a}$., D.S., Universidade Estadual do Mato Grosso do Sul, CassilândiaMS, <cgmendon@terra.com.br>.

Planta Daninha, Viçosa-MG, v. 23, n. 1, p. 1-7, 2005 


\section{INTRODUÇÃO}

A utilização de um mesmo sistema de manejo de solo por muitos anos consecutivos pode modificar a flora vegetativa na superficie do solo e alterar o tamanho e a composição do banco de sementes.

O banco de sementes é uma reserva de sementes viáveis no solo presente na superficie ou em profundidade. A variabilidade e densidade botânica de um povoamento de sementes no solo, em um dado momento, são o resultado do balanço entre entrada de novas sementes e perdas por germinação, deterioração, parasitismo, predação e transporte (Carmona, 1992).

Técnicas que promovem a inversão das camadas de solo, como a aração, resultam na melhor distribuição das sementes ao longo do perfil e no enterrio de grande quantidade delas, podendo inviabilizar a capacidade de regeneração de parte da população de sementes em certas espécies. Já os métodos que não promovem a inversão de camadas permitem que a maioria das sementes permaneça próximo à superficie do solo. Essa proximidade da superficie do solo, segundo Ball (1992), proporciona maior germinação das sementes e estabelecimento de plantas daninhas, quando comparado com outros métodos de sistemas de cultivos.

Além de influenciarem a distribuição vertical das sementes de plantas daninhas no solo, os sistemas de cultivo também exercem influência no tamanho deste. Carmona (1995) estimou o banco de sementes em quatro agrossistemas distintos: área de rotação de culturas (soja, pousio e feijão), várzea, pomar de citros e pastagem de Brachiaria brizantha. A quantidade média de sementes por metro quadrado foi de 22.313 na várzea, 6.768 na área de rotação, 3.595 nas coroas do pomar e 529 na pastagem. Foi constatado que a similaridade do tamanho do banco de sementes entre agroecossistemas é maior nas áreas mais perturbadas, como as de rotação de culturas, várzea e coroas do pomar.

As informações sobre tamanho e composição do banco de sementes são importantes para a elaboração de estratégias de manejo integrado de plantas daninhas. A observação in situ da emergência de plântulas no campo pode dar uma indicação geral sobre o tamanho e a composição da população vegetativa e do banco de sementes na área. Entretanto, esse método não é preciso, pois várias sementes podem permanecer viáveis no solo por um longo período sem germinar e algumas sementes germinadas não chegam a emergir, devido às condições ambientais desfavoráveis ou profundidades excessivas de enterrio.

A técnica mais utilizada na determinação do número de sementes é a estimativa da emergência de plântulas diretamente a partir da amostra de solo, que, por sua vez, deve ser espalhado em fina camada sobre recipientes acondicionados em casa de vegetação, a fim de assegurar as condições ambientais favoráveis ao surgimento de plântulas (Putwain \& Gillham, 1990). No entanto, esse método de germinação geralmente subestima o banco de sementes, porque as sementes das plantas daninhas apresentam diferentes fluxos de emergência, podendo germinar ou não durante a avaliação (Gross, 1990). Para que a determinação seja mais confiável, o ensaio deve ser realizado por períodos longos.

Os objetivos desta pesquisa foram fazer o levantamento da população vegetativa e determinar a quantidade de sementes viáveis e sua distribuição no perfil do solo em área sob dois sistemas de manejo de solo.

\section{MATERIAL E MÉTODOS}

Os ensaios foram realizados no Departamento de Produção Vegetal da ESALQ/USP, em área irrigada e sob dois tipos de manejo de solo. O ensaio A caracterizou-se como área convencional de preparo de solo (aração e gradagem) para cultivo de milho no verão e pousio no inverno. No ensaio B, o solo permaneceu em pousio por um período de sete anos, sendo as plantas daninhas manejadas somente com herbicidas e roçadeira, ou seja, sem utilização de implementos agrícolas revolvedores de solo. Sempre que necessárias, irrigações foram feitas no ensaio A com sistema pivô central para atender às exigências hídricas da cultura do milho; conseqüentemente, irrigou-se o ensaio B, pelo fato de este situar-se ao lado do ensaio A e sob o pivô central.

Cada ensaio foi amostrado 28 vezes (parcelas de $2,5 \times 6,0 \mathrm{~cm})$. A identificação e 
quantificação das espécies de plantas daninhas nos sistemas estudados foram determinadas pela retirada de 20 amostras simples de solo, em cada parcela, nas profundidades de $0,0-2,5 ; 2,5-5,0 ; 5,0-10,0 ; 10,0-15,0$; e $15,0-20,0 \mathrm{~cm}$, com trado de ferro de $3,14 \mathrm{~cm}$ de diâmetro. À medida que se retiravam as camadas de solo, estas eram colocadas em dois baldes plásticos (ambos identificados), ensacadas e enviadas ao laboratório, onde ficaram em repouso por uma semana em área coberta, para ocorrer perda do excesso de umidade. Feito isso, em cada amostra composta retiravam-se alíquotas de um quilograma, que foram colocadas em bandejas de aluminio (20 x $30 \mathrm{~cm}$ ) perfuradas no fundo, para permitir a percolação do excesso de água. As bandejas foram identificadas com suas respectivas profundidades de solo e acondicionadas aleatoriamente em casa de vegetação sob irrigação diária. A identificação e quantificação de plântulas/bandeja foram feitas em quatro épocas: 15, 30, 60 e 90 dias. A cada contagem, as plântulas identificadas foram arrancadas, a fim de permitir novo fluxo de emergência.

Para estimar a quantidade de sementes viáveis no solo, nos dois sistemas de manejo, foi utilizada a fórmula (Monqueiro \& Christoffoleti, 2003): número de plântulas emergidas/amostra de solo $(\mathrm{kg})$ = número provável de sementes viáveis por hectare/ $2.600 .000 \mathrm{~kg}$, em que se considerou a fatia de solo de $20 \mathrm{~cm}$ - camada efetiva arável - e a densidade do solo de $1,3 \mathrm{~g} \mathrm{~cm}^{3}$, determinada no laboratório do Departamento de Solos e Nutrição de Plantas da ESALQ/USP, para calcular o peso do solo $(2.600 .000 \mathrm{~kg})$. A distribuição de sementes viáveis no perfil do solo foi determinada pela contagem de plântulas emergidas nas fatias de solo: $0,0-2,5 ; 2,5-5,0 ; 5,0-10,0 ; 10,0-15,0$; e $15,0-20,0 \mathrm{~cm}$. Os dados foram analisados estatisticamente pelo programa SANEST e as médias comparadas pelo teste de Tukey $(\mathrm{P}<0,05)$.

\section{RESULTADOS E DISCUSSÃO}

\section{Identificação da flora vegetativa}

$\mathrm{Na}$ área em pousio foram identificadas 12 espécies de dicotiledôneas e 8 famílias, destacando-se as famílias Compositae e Amaranthaceae, com quatro e duas espécies, respectivamente. As espécies que mais ocorreram foram Gnaphalium spicatum (macela), Leonotis nepetaefolia (cordão-de-frade) e Alternanthera tenella (apaga-fogo), com 40,1, 28,6 e 18,2\%, respectivamente (Tabela 1). Entre as monocotiledôneas foram identificadas cinco espécies e duas famílias, destacando-se a família Gramineae, com quatro espécies. As espécies que mais ocorreram foram Eleusine indica (pé-de-galinha), Digitaria horizontalis (capim-colchão) e Commelinea benghalensis (trapoeraba), com 69,6, 15,0 e $7,1 \%$, respectivamente.

$\mathrm{Na}$ área com sistema de manejo de solo convencional foram identificadas 19 espécies de dicotiledôneas e 10 famílias, destacandose as famílias Compositae e Cruciferaceae, com seis e três espécies, respectivamente. As espécies que mais ocorreram foram Ageratum conyzoides (mentrasto), Leonotis nepetaefolia (cordão-de-frade) e Richardia brasiliensis (poaia), com 46,6, 11,2 e 10,5\%, respectivamente (Tabela 2). Entre as monocotiledôneas foram identificadas cinco espécies e duas famílias, destacando-se a família Gramineae, com quatro espécies. As espécies que mais ocorreram foram Digitaria horizontalis (capimcolchão), Eleusine indica (pé-de-galinha) e Setaria geniculata (rabo-de-gato), com 43, 1, 30,6 e $12,7 \%$, respectivamente.

Erasmo et al. (2004) fizeram o levantamento fitossociológico de comunidades de plantas daninhas em áreas de produção de arroz irrigado cultivado sob diferentes sistemas de manejo de solo e verificaram que, na área sem rotação de cultura há mais de cinco anos, houve predomínio de espécies das famílias Poaceae e Compositae. Em área rotacionada com a cultura de soja há mais de cinco anos, predominaram espécies das famílias Poaceae e Cyperaceae, enquanto na área rotacionada com a cultura de melancia há mais de dois anos predominaram as famílias Euphorbiaceae e Lamiaceae.

\section{Quantificação de sementes viáveis e sua distribuição no perfil do solo}

Na Tabela 3 encontram-se os resultados da estimativa do número de sementes viáveis

Planta Daninha, Viçosa-MG, v. 23, n. 1, p. 1-7, 2005 
por hectare na camada de $0-20 \mathrm{~cm}$ de profundidade de solo em função das plântulas emergidas. A quantidade encontrada na área convencional e em pousio foi de 61,88 e 38,74 milhões ha ${ }^{-1}$, respectivamente, sendo os valores significativamente diferentes entre si. Os maiores fluxos de emergência ocorreram aos 15 e 60 dias em ambos os sistemas de manejo de solo; na média geral, eles foram de 15,5 e 9,7 milhões ha ${ }^{-1}$ na área com sistemas convencional e pousio, respectivamente.

Os maiores valores de sementes viáveis de plantas daninhas no sistema convencional ocorreram talvez devido às constantes perturbações do solo pela utilização de implementos agrícolas no preparo de solo para plantio da cultura de milho no verão. Isso fez com que as sementes localizadas em grandes profundidades viessem à superficie do solo, propiciando condições para que germinassem e, assim, incrementassem o banco de sementes, já que os implementos agrícolas (arado) têm a capacidade de atingir profundidades de 20 a $25 \mathrm{~cm}$, dependendo da umidade, da velocidade de trabalho e das propriedades físicas do solo. Todavia, a aração muito profunda pode inviabilizar a capacidade de regeneração de parte da população de sementes em certas espécies, pois, segundo Carmona (1992), poucas espécies invasoras podem emergir em profundidade superior a $5 \mathrm{~cm}$, à exceção daquelas com sementes grandes. Froud-Williams et al. (1983) observaram que a aração realizada na profundidade de $20 \mathrm{~cm}$ do solo erradicou sementes de Bromus sterilis; apesar de algumas germinarem, elas não conseguiram emergir.

O fato de sementes posicionadas em profundidades superiores a $20 \mathrm{~cm}$ no solo não germinarem é provocado por fatores extrinsecos. Segundo Castro \& Vieira (2001), a exposição à luz vermelha (660 a $760 \mathrm{~nm}$ ) de sementes embebidas causa transformação do fitocromo (Fv) em uma forma ativa (Fve), a qual estimula a germinação. Quando a semente é exposta ao comprimento de luz vermelho distante (760 a $800 \mathrm{~nm})$, ocorre o inverso e o processo germinativo é inibido.

Também as operações de aplicação de herbicidas e corte das plantas efetuadas por roçadeira antes da floração e formação de sementes, durante sete anos em que a área permaneceu em pousio, podem ter ocasionado uma menor reserva de sementes viáveis no solo. Outros fatores que podem ter contribuído

Tabela 1 - Plantas daninhas dicotiledôneas e monocotiledôneas presentes na área sob sistema de manejo de solo em pousio

\begin{tabular}{|c|c|c|c|}
\hline Família & Nome científico & Nome comum & Ocorrência $(\%)$ \\
\hline \multicolumn{4}{|c|}{ Dicotiledôneas } \\
\hline Compositae & Gnaphalium spicatum & Macela & 40,1 \\
\hline Labiatae & Leonotis nepetaefolia & Cordão-de-frade & 28,6 \\
\hline Amaranthaceae & Amaranthus tenella & Apaga-fogo & 18,2 \\
\hline Compositae & Emmilia sonchifolia & Falsa-serralha & 3,7 \\
\hline Rubiaceae & Richardia brasiliensis & Poaia & 3,4 \\
\hline Compositae & Parthenium hysterophorus & Losna-branca & 3,4 \\
\hline Cruciferae & Lepidium virginicum & Mentruz & 1,0 \\
\hline Amaranthaceae & Amaranthus deflexus & Caruru & 0,7 \\
\hline Covolvulaceae & Ipomoea grandifolia & Corda-de-viola & 0,3 \\
\hline Compositae & Ageratum conyzoides & Mentrasto & 0,3 \\
\hline Leguminosae & Indigofera hirsuta & Anileira & 0,2 \\
\hline Malvaceae & Sida spp. & Guanxuma & 0,1 \\
\hline \multicolumn{4}{|c|}{ Monocotiledôneas } \\
\hline Gramineae & Eleusina indica & Pé-de-galinha & 69,7 \\
\hline Gramineae & Digitaria horizontalis & Capim-colchão & 15,0 \\
\hline Commelinaceae & Commelina benghalensis & Trapoeraba & 7,1 \\
\hline Gramineae & Cenchrus. echinatus & Capim-carrapicho & 4,7 \\
\hline Gramineae & Setaria geniculata & Capim-rabo-de-gato & 3,6 \\
\hline
\end{tabular}


para o esgotamento das sementes no solo são os restos vegetais, ou cobertura morta, presentes no sistema de pousio, que, pela sua decomposição, produziram compostos químicos que podem ter afetado as sementes (alelopatia), além da predação pelos animais, pelo fato de estas se situarem na superfície do solo. De acordo com Pitelli (1997), a redução do distúrbio do solo resultante da adoção do plantio direto provoca uma diminuição temporária das populações de plantas daninhas nos agroecossistemas, em razão de as sementes produzidas após a adoção do plantio direto ficarem depositadas numa camada superficial do solo, sendo mais suscetíveis à ação dos predadores de grande porte, como pássaros e roedores.

Tabela 2 - Plantas daninhas dicotiledôneas e monocotiledôneas presentes na área sob sistema de manejo de solo convencional

\begin{tabular}{|c|c|c|c|}
\hline Família & Nome científico & Nome comum & Ocorrência $(\%)$ \\
\hline \multicolumn{4}{|c|}{ Dicotiledôneas } \\
\hline Compositae & Ageratum conyzoides & Mentrasto & 46,6 \\
\hline Labiatae & Leonotis nepetaefolia & Cordão-de-frade & 11,2 \\
\hline Rubiaceae & Richardia brasiliensis & Poaia & 10,5 \\
\hline Amaranthaceae & Amaranthus tenella & Apaga-fogo & 6,8 \\
\hline Compositae & Parthenium hysterophorus & Losna-branca & 6,4 \\
\hline Compositae & Gnaphalium spicatum & Macela & 5,2 \\
\hline Compositae & Galinsoga parviflora & Picão-branco & 5,1 \\
\hline Amaranthaceae & Amaranthus deflexus & Caruru & 1,8 \\
\hline Cruciferae & Lepidium virginicum & Mentruz & 1,4 \\
\hline Compositae & Acanthospermum hispidum & Carrapicho-de-carneiro & 1,3 \\
\hline Compositae & Emmilia sonchifolia & Falsa-serralha & 1,3 \\
\hline Portulacaceae & Portulaca oleracea & Beldroega & 0,4 \\
\hline Oxalidaceae & Oxalis latifolia & Trevo & 0,4 \\
\hline Covolvulaceae & Ipomoea grandifolia & Corda-de-viola & 0,3 \\
\hline Cruciferaceae & Lepidium virginicum & Mastruz & 0,3 \\
\hline Labiatae & Hyptis suaveolens & Cheirosa & 0,4 \\
\hline Cruciferaceae & Coronopus didymus & Mastruço & 0,2 \\
\hline Malvaceae & Sida spp. & Guanxuma & 0,2 \\
\hline Solanaceae & Solanum americanum & Maria-preta & 0,2 \\
\hline \multicolumn{4}{|c|}{ Monocotiledôneas } \\
\hline Gramineae & Digitaria horizontalis & Capim-colchão & 43,1 \\
\hline Gramineae & Eleusina indica & Pé-de-galinha & 30,6 \\
\hline Gramineae & Setaria geniculata & Capim-rabo-de-gato & 12,7 \\
\hline Commelinaceae & Commelina. benghalensis & Trapoeraba & 11,4 \\
\hline Gramineae & Cenchrus echinatus & Capim-carrapicho & 2,1 \\
\hline
\end{tabular}

Tabela 3 - Número total e média de plântulas emergidas (milhões ha ${ }^{-1}$ ) na camada de 0-20 $\mathrm{cm}$ de profundidade do solo nos sistemas convencional e pousio, avaliadas aos 15, 30,60 e 90 dias após as bandejas serem acondicionadas em casa vegetação

\begin{tabular}{|c|c|c|c|c|c|c|}
\hline \multirow{2}{*}{ Sistema } & \multicolumn{5}{|c|}{ Época de avaliação (dias) } & \multicolumn{2}{c|}{$\begin{array}{c}\text { Total de } \\
\text { plântulas }\end{array}$} & $\begin{array}{c}\text { Média de } \\
\text { plântulas }\end{array}$ \\
\cline { 2 - 6 } & 15 & 30 & 60 & 90 & $61,88 \mathrm{a}$ & $15,47 \mathrm{a}$ \\
\hline Convencional & $16,38 \mathrm{a}$ & $7,28 \mathrm{a}$ & $35,10 \mathrm{a}$ & $3,12 \mathrm{a}$ & $38,74 \mathrm{~b}$ & $9,68 \mathrm{~b}$ \\
\hline Pousio & $13,00 \mathrm{~b}$ & $3,90 \mathrm{~b}$ & $20,28 \mathrm{~b}$ & $1,56 \mathrm{~b}$ & $3 . \cdots \cdots \cdots$ \\
\hline
\end{tabular}

Médias seguidas da mesma letra na coluna não diferem estatisticamente entre si pelo teste t a $5 \%$ de probabilidade. 
A comprovação de que a operação de revolvimento do solo ocasiona a homogeneização do número de sementes no perfil de solo e o deslocamento destas para as camadas mais profundas está representada na Figura 1, onde encontra-se o número de sementes viáveis por hectare, nas profundidades de $0-2,5 ; 2,5-5,0$; $5,0-10,0 ; 10,0-15,0$; e 15,0-20,0 cm, nos dois sistemas de manejo do solo.

Verificou-se que o número de sementes viáveis nas amostras de solo retiradas no sistema em pousio na profundidade de $0-2,5 \mathrm{~cm}$ foi significativamente superior ao das demais profundidades; à medida que as amostragens foram efetuadas em maiores profundidades, o número de sementes foi diminuindo chegando a 2,9 milhões ha-1 na camada de 15,0-20,0 cm. No sistema convencional ocorreu o inverso: Foram estimados 8,6 milhões ha ${ }^{-1}$ de sementes viáveis na camada de $0,0-2,5 \mathrm{~cm}$, porém, à medida que as amostragens foram realizadas no sentido da superficie para as camadas mais profundas do solo, houve aumento do número de sementes viáveis - exceto na camada de 10,0-15,0 cm, onde se estimaram
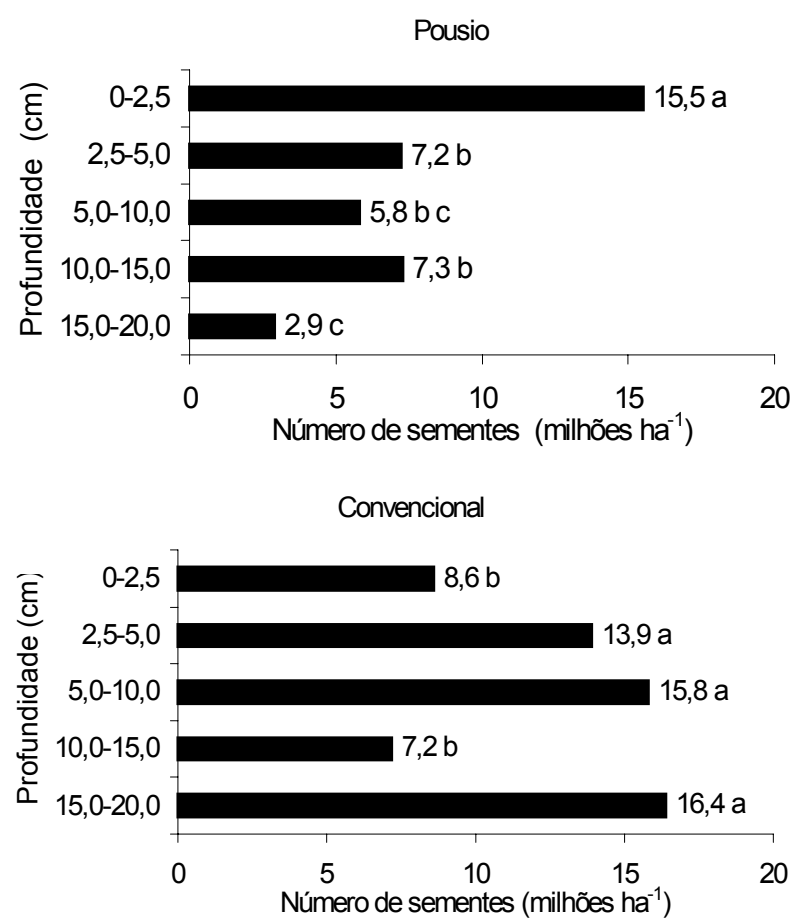

Figura 1 - Distribuição de sementes viáveis (milhões ha ${ }^{-1}$ ) no perfil do solo, amostradas nas profundidades de $0-2,5$; 2,5-5,0; 5,0-10,0;10,0-15,0; e 15,0-20,0 cm, em áreas de plantio convencional e pousio.
7,2 milhões ha-1 - , atingindo 16,4 milhões ha ${ }^{-1}$ na profundidade de $15,0-20,0 \mathrm{~cm}$.

Schreiber (1992), estudando os efeitos de preparo do solo, rotação de culturas e uso de herbicidas sobre a dinâmica da população de Setaria faberi, em Purdue, EUA, no período de 1981 a 1991, verificou que a distribuição de sementes no solo, quando da realização de preparo mínimo ou plantio direto, concentrouse nos $2,5 \mathrm{~cm}$ superficiais, enquanto as operações de preparo de solo convencional levaram à distribuição das sementes até $20 \mathrm{~cm}$ de profundidade no perfil do solo.

$\mathrm{Na}$ área de pousio, ocorreu menor número de espécies e sementes viáveis no solo; as familias dominantes foram Compositae e Amaranthacea e as sementes concentraramse nas camadas superficiais do solo $(0-2,5 \mathrm{~cm})$. $\mathrm{Na}$ área convencional, as famílias dominantes foram Compositae e Cruciferaceae e as sementes viáveis encontraram-se dispersas no perfil do solo.

\section{LITERATURA CITADA}

BALL, D. A. Weed seedbank response to tillage, herbicides, and crop rotation sequence. Weed Sci., v. 14, p. 654-659, 1992.

CARMONA, R. Problemática e manejo de bancos de sementes de invasoras em solos agrícolas. Planta Daninha, v. 10, p. 5-16, 1992.

CARMONA, R. Banco de sementes e estabelecimento de plantas daninhas em agroecossistemas. Planta Daninha, v. 13, p. 3-9, 1995.

CASTRO, P. R. C.; VIEIRA, E. L. Aplicações de reguladores vegetais na agricultura tropical. Guaíba: Agropecuária, 2001. 132 p.

ERASMO, E. A. L.; PINHEIRO, L. L. A.; COSTA, N. V. Levantamento fitossociológico das comunidades de plantas infestantes em áreas de produção de arroz irrigado cultivado sob diferentes sistemas de manejo. Planta Daninha, v. 22, p. 195-201, 2004.

FROUD-WILLIAMS, R. J.; CHANCELLOR, R. J.; DRENNAN, D. S. H. Influence of cultivation regime upon buried weed seed in arable cropping systems. J. Appl. Ecol., v. 20, p. 199-208, 1983.

GROSS, K. L. A. A comparison of methods for estimating seed numbers in the soil. J. Ecol., v. 78, p. 1079-1093, 1990. 
MONQUEIRO, P. A.; CHRISTOFFOLETI, P. J. Dinâmica do banco de sementes em áreas com aplicação freqüente do herbicida glyphosate. Planta Daninha, v. 21, p. 63-69, 2003.

PITELLI, R. A. Dinâmica de plantas daninhas no sistema plantio direto. In: SIMPÓSIO SOBRE HERBICIDAS E PLANTAS DANINHAS, 1., 1997, Dourados. Anais... Dourados: EMBRAPA-CPAO, 1997. p. 50-61.
PUTWAIN, P. D.; GILLHAM, D. A. The significance of the dormant viable seed banks in the restoration of heathlandas. Biol.Conser., v. 52, p. 1-16, 1990.

SCHREIBER, M. M. Influences of tillage, crop rotation, and weed management on grant foxtait (Setaria faberi) population dynamics and corn yield. Weed Sci., v. 40, p. 645-653, 1992. 